DOI https://doi.org/10.15407/csc.2020.06.029

UDC 364.2:331; 681.513

L.M. KOLIECHKINA, Doctor of Physical and Mathematical Sciences, Professor,

University of Lodz,

22 Banaha st., Lodz, 90-238, Poland,

lkoliechkina@gmail.com

A.M. NAHIRNA, PhD, Physical and Mathematical, Associate Professor,

National University of "Kyiv-Mohyla Academy",

2 Skovoroda st. , Kyiv, 04070, Ukraine,

naghirnaalla@ukr.net

\title{
Finding the Optimal Solution \\ to the Problem of Conditional Optimization on the Graph of the Set of Partial Permutations
}

An optimization problem on a combinatorial set of partial permutations with additional constraints is formulated in the paper. An algorithm for solving this type of problem is considered, which consists of four steps. The algorithm lies in constructing a graph of a set of partial permutations to find the optimal solution. An example of a practical implementation of the presented algorithm is given.

Keywords: conditional optimization problem, optimal solution, graph, subgraph, of the Set of Partial Permutations, objective function, constraints.

\section{Introduction}

From a practical point of view, a significant number of applied problems are modeled by combinatorial optimization problems, as evidenced by the variety of scientific works of both foreign and domestic authors [1-8]. The problem of combinatorial optimization consists of finding the optimum of the objective function on combinatorial sets. It should be noted that quite often problems of this class are difficult to compute and cumbersome, because a full enumeration of options, as a solution method, is applicable only for problems of insignificant dimension. Therefore, there is an urgent need to improve existing methods and develop new approaches and algorithms [9-13]. When immersed in Euclidean space, combinatorial sets acquire a number of interesting properties that allow considering various original approaches to solving and increasing the efficiency of traditional combinatorial optimization methods [14-17].

\section{Formulation of the Problem}

Consider an arbitrary finite set $A$ consisting of $n$ various elements, from which different ones are selected $k(n \leq k)$. An ordered set of $k$ different elements from a set $A$ is called an arrangement of $n$ elements by and $k$ is denoted by $A_{n}^{k}[12,14,17]$.

Then the optimization problem with additional constraints will have the form:

$$
Z\left(\Phi, A_{n}^{k}\right): \max \left\{\Phi(a) \mid a \in A \subset A_{n}^{k}\right\},
$$




$$
D=\left\{x \in E_{k}^{n} \subset R^{n} \mid G x \leq(\geq) b\right\},
$$

where $A$ is a subset of the combinatorial set of partial permutations $A_{n}^{k}$.

Let us carry out a bijective mapping of the set $A_{n}^{k}$ into space $R^{n}$ by assigning a vector $x \in R^{n}$ to each element $a \in A_{n}^{k}$. The image of a $A_{n}^{k}$ set is denoted by $E_{K}^{n} \subset R^{n}[15,17]$. As a result, we have a combinatorial optimization problem in the Euclidean setting:

$$
\begin{gathered}
Z\left(F, E_{n}^{k}\right): \max \left\{F(a) \mid X \in D \subset E_{n}^{k}\right\}, \\
D=\left\{x \in E_{k}^{n} \subset R^{n} \mid G x \leq(\geq) b\right\},
\end{gathered}
$$

where $\Phi(a)=F(a)$ for $a \in A_{n}^{k}, x \in E_{k}^{n}$,

$$
F(x)=\sum_{j=1}^{n} c_{j} x_{j}
$$

The location polytope $M\left(A_{n}^{k}\right)$ under $(n>k)$ is combinatorially equivalent to the partial permutations polytope of $k$ dimension $M\left(P_{k}\right)$ [17]. Then, $X$ is a non-empty set in $R^{n}$, which will be denoted as follows: $X=\operatorname{vertM}\left(A_{n}^{k}\right)$, $M=\operatorname{conv} P_{k}[14]$.

\section{Algorithm for Solving}

The algorithm for solving problem (3) - (5) consists of the following steps.

$\mathrm{S} t \mathrm{e} \mathrm{p}$ 1. Ordering the coefficients of the objective function in ascending order. If the objective function coefficients are ordered in ascending order by condition, then we leave them unchanged. Otherwise, it is necessary to transform the coefficients of the objective function into new ones by transposition of elements, taking into account the condition of their ordering in non-decreasing or$\operatorname{der}: c_{1}^{\prime} \leq c_{2}^{\prime} \leq \ldots \leq c_{k}^{\prime}$.

Table 1. The last elements at the points of the graph of the set of partial permutations

\begin{tabular}{|c|c|c|c|}
\hline $\begin{array}{c}\text { Last } \\
\text { element } a_{n}\end{array}$ & $\ldots$ & $\begin{array}{c}\text { Last } \\
\text { element } a_{2}\end{array}$ & $\begin{array}{c}\text { Last } \\
\text { element } a_{1}\end{array}$ \\
\hline$a_{n-1} a_{n}$ & & $a_{n} a_{2}$ & $a_{n} a_{1}$ \\
$a_{n-2} a_{n}$ & $\ldots$ & $a_{n-1} a_{2}$ & $a_{n-1} a_{1}$ \\
$\ldots$ & $\ldots$ & $\ldots$ & $\ldots$ \\
$a_{1} a_{n}$ & $\ldots$ & $\ldots a_{2}$ & $\ldots a_{1}$ \\
\hline
\end{tabular}

We get the display:

$\Delta u_{1}: N \rightarrow C: \Delta u_{1}=\left(\begin{array}{cccc}x_{1}^{1} & x_{2}^{1} & \ldots & x_{k}^{1} \\ u^{-1}(1) & u^{-1}(2) & \ldots & u^{-1}(k)\end{array}\right),(6)$

where $\left(x_{1}^{1}, x_{2}^{1}, \ldots, x_{k}^{1}\right)$ - point set of partial permutations, $u(k)$ - the location of each element of a certain point in the set of partial permutations.

$\mathrm{S}$ te $\mathrm{p} 2$. Constructing a table $(r \times s)$ that displays the $n^{\prime}$-last elements of the set of partial permutations.

Because the, $A=\left(a_{1}, a_{2}, \ldots, a_{n}\right)$, and $A_{n}^{k}$, then

$$
s=n ; r=s-1 \text {. }
$$

The number of the last elements is determined by the positive coefficients of the objective function $c_{j} \geq 0$. If there are no such coefficients, then half of the largest coefficients by modulus are considered.

The number of subgraphs of the set of partial permutations $k$ is equal to:

$$
k=r \times s .
$$

Each subgraph consists of $q_{i}(i=1, \ldots, k)$ points set of partial permutations:

$$
q_{i}=A_{n}^{k} / k \text {. }
$$

$\mathrm{S}$ t e $\mathrm{p}$ 3. Building a subgraph $q_{i}(i=1, \ldots, k)$ graph set of partial permutations.

It should be noted that each subgraph of the graph of the set of partial permutations is constructed according to the decreasing values of the objective function. Consequently, the first point of the ordered subset of partial permutations will give the largest value of the objective function (Fig. 1).

At each level of the subgraph of the set of partial permutations, the calculation is carried out:

$$
\Delta g_{j}^{e x t r}=a_{i j} \cdot x_{1}+a_{i j} \cdot x_{2}(\leq, \geq,>,<) b_{j} .
$$

The subgraph level is determined by lines, from left to right.

$\mathrm{S} t \mathrm{e} p \mathrm{p}$. Finding the optimal solution on the graph of the set of partial permutations. If condition (10) is satisfied, then at a given level of a certain subgraph of the set of partial permutations, all its points satisfy the checked constraint. According to step 3, the first point ensures the maximization of the objective function; therefore, it is necessary to take into account only the points of the highest levels. 
1-level

k-level

Fig. 1. Subgraph of a graph of a set of partial permutations n-level

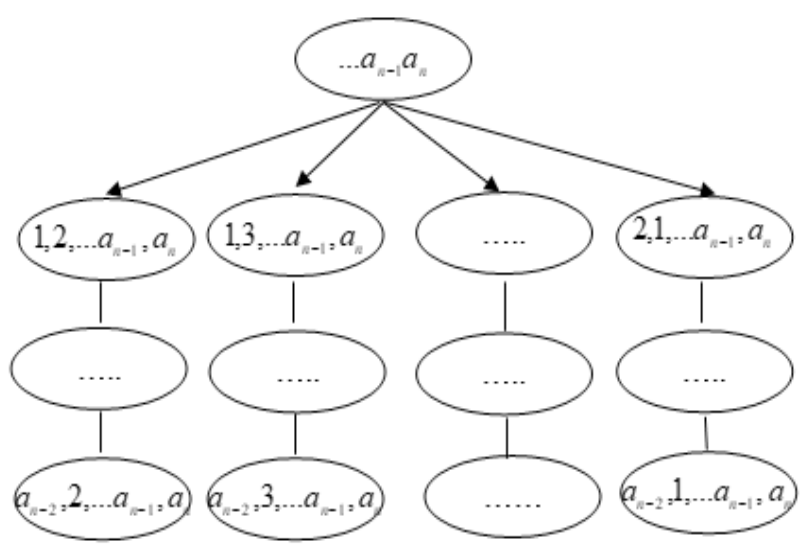

If (10) is not satisfied, then this subgraph must be excluded from further consideration.

In the case of one-sided fulfillment of (10), i.e., satisfies $\Delta g_{j}^{\max }$ or $\Delta g_{j}^{\min }$, it is necessary to consider the points of the subgraph of the level set of partial permutations an order of magnitude lower and carry out calculations based on formula (10).

Next, consider an example, for the solution of which the considered algorithm will be used.

\section{Example}

It is necessary to find the maximum value of the function $F(x)=-4 x_{1}-0.5 x_{2}+3 x_{3}+11 x_{4}$ on set of partial permutations $A_{6}^{4}$, where $A=(1,2,3,4,5,6)$, and subject to the following linear constraints:

$$
\left\{\begin{array}{l}
g_{1}=2 x_{1}-3 x_{2}+4 x_{3}+6 x_{4} \geq 7, \\
g_{2}=8 x_{1}+3 x_{2}-5 x_{3}+2 x_{4} \leq 19, \\
g_{3}=6 x_{1}-4 x_{2}+7 x_{3}+5 x_{4} \leq 31 .
\end{array}\right.
$$

Decision:

Since the coefficients of the objective function are ordered in ascending order, there is no need to consider the mapping (6).

Let's build a graph of a set of partial permutations. For this, we will form table 1.

Building a table $(r \times s)$ (table 1).

Since, $A_{6}^{4}$, where $A=(1,2,3,4,5,6)$, then taking into account (7) we have:

$$
\begin{aligned}
& s=n=6 ; \\
& r=s-1=6-1=5 .
\end{aligned}
$$

Since, $c_{3}=>0$ and $c_{4}=1>0$.

Then table 2 in its structure will display the last two elements at the points of the graph of the set of partial permutations.

The number of esubgraphs of the set of partial permutations $k(8)$ :

$$
k=r \times s=5 \times 6=30
$$

Table 2. The last two elements at the points of the graph of the set of partial permutations

\begin{tabular}{|c|c|c|c|c|c|}
\hline \multicolumn{7}{|c|}{ Last element } \\
\hline 1 & 2 & 3 & 4 & 5 & 6 \\
\hline 56 & 65 & 64 & 63 & 62 & 61 \\
46 & 45 & 54 & 53 & 52 & 51 \\
36 & 35 & 34 & 43 & 42 & 41 \\
26 & 25 & 24 & 23 & 32 & 31 \\
16 & 15 & 14 & 13 & 12 & 21 \\
\hline
\end{tabular}




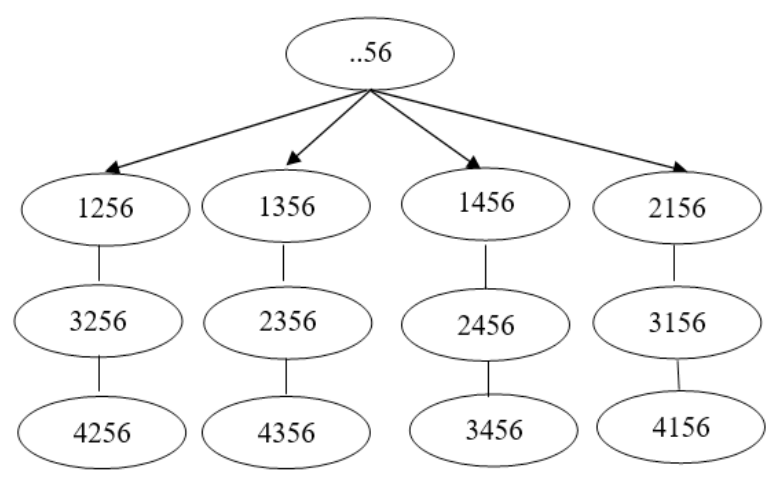

Fig. 2. The first subgraph of the set of partial permutations, which has the last two elements at points 56

Each subgraph consists of $q_{i}(i=1, \ldots, k)$ points set of partial permutations (9):

$$
q_{i}=A_{n}^{k} / k=360 / 30=12 .
$$

Building a subgraph $q_{i}(i=1, \ldots, k)$ graph set of partial permutations.

Consider the first subgraph of the form 56 (Fig. 2).

We check the fulfillment of the first constraint on the first subgraph 56 using (10):

$$
g_{1}=2 x_{1}-3 x_{2}+4 x_{3}+6 x_{4} \geq 7 .
$$

Then, for the entire branch 56:

$$
\begin{aligned}
& \Delta g_{1}=2 x_{1}-3 x_{2}, \\
& \Delta g_{1}\left(x_{1}, x_{2}, 5,6\right) \geq 7-4 \cdot 5-6 \cdot 6, \\
& \Delta g_{1} \geq-49 .
\end{aligned}
$$

Since, $g_{1} \geq 7$, then we will assume that $g_{1} \rightarrow \max$.

Consider the points at which $\Delta g_{1} \rightarrow \max$ and $\Delta g_{1} \rightarrow \min$, where

$$
\Delta g_{1}=2 x_{1}-3 x_{2} \text {. }
$$

Finding $\Delta g_{1}^{\max }(4,1,5,6)$ :

$$
\Delta g_{1}^{\max }=2 \cdot 4-3 \cdot 1=5 \text {, i.e. }
$$

$\Delta g_{1}^{\max }=5 \geq-49$, therefore the bound $\Delta g_{1} \geq 7$ performed.

Finding $\Delta g_{1}^{\min }(1,4,5,6)$ :

$$
\begin{aligned}
& \Delta g_{1}^{\min }=2 \cdot 1-3 \cdot 4=-10, \text { i.e. }, \\
& \Delta g_{1}^{\min }(1,4,5,6)=-10>-49 .
\end{aligned}
$$

Accordingly, it $\Delta g_{1} \geq 7$ is carried out for all other points of subgraph 56 .

Then, the point $(1,2,5,6)$ of the set of partial permutations at which the maximum value of the objective function is reached on branch 56 will satisfy the 1-st constraint: $F_{1}^{\max }(1,2,5,6)=76$.

We check the execution of the second constraint on the entire branch 56 :

$$
g_{2}=8 x_{1}+3 x_{2}-5 x_{3}+2 x_{4} \leq 19 .
$$

Then for the entire branch 56 the following should be done:

$$
\begin{aligned}
& \Delta g_{2}=8 x_{1}+3 x_{2}, \\
& \Delta g_{2}\left(x_{1}, x_{2}, 5,6\right) \leq 19+5 \cdot 5-2 \cdot 6, \\
& \Delta g_{2} \leq-32 .
\end{aligned}
$$

Finding $\Delta g_{2}^{\min }(1,2,5,6)$ :

$$
\begin{aligned}
& \Delta g_{2}^{\min }=8 \cdot 1+3 \cdot 2=12 \text {, i.e., } \\
& \Delta g_{2}^{\min }(1,2,5,6)=12 \leq 32 .
\end{aligned}
$$

Since, $g_{2} \leq 19$, i.e., we can assume that $g_{2} \rightarrow \min$. Then you need to find

$$
\Delta g_{2}^{\max }=8 \cdot 4+3 \cdot 3=41 \text {, i.e., }
$$
satisfied.

$\Delta g_{2}^{\max }(4,3,5,6)=41>32$, inequality is not

By how many, the restriction $g_{2} \leq 19$ is met, that is, the points at which this restriction is met. at.

Consider $\Delta g_{2}^{\text {extr }}=a_{21} \cdot x_{1}+a_{22} \cdot x_{2}$ each level a subgraph

For 1-st level: $\Delta g_{2}^{\max }(1,4,5,6)=20<32$, $\Delta g_{2}^{\min }(1,2,5,6)=12 \leq 32$, all other points satisfy the 2-nd inequality.

For $\quad 2$-nd: $\quad \Delta g_{2}^{\max }(3,2,5,6)=30<32$, $\Delta g_{2}^{\min }(2,3,5,6)=25<32$, all other points satisfy the 2-nd inequality.

For $\quad 3$-rd: $\quad \Delta g_{2}^{\max }(4,3,5,6)=41>32$, $\Delta g_{2}^{\min }(4,1,5,6)=35>19$, accordingly, this inequality does not hold for all other points of this level.

After checking the 2-nd constraint, subgraph 56 will look like (Fig. 3).

We check the fulfillment of the third additional constraint using the points of the subgraph, according to Fig. 3:

$$
g_{3}=6 x_{1}-4 x_{2}+7 x_{3}+4 x_{4} \leq 31,
$$




$$
\begin{aligned}
& \Delta g_{3}=6 x_{1}-4 x_{2}, \\
& \Delta g_{3}\left(x_{1}, x_{2}, 5,6\right) \leq 31-7 \cdot 5-5 \cdot 6, \\
& \Delta g_{3} \leq-34 .
\end{aligned}
$$

How much, $\Delta g_{3} \leq 31$, i.e., we can assume that $g_{3} \rightarrow \min$. Since the constraint is not met, it is necessary to find $\Delta g_{3}^{\text {extr }}$ :

$$
\begin{aligned}
& \Delta g_{3}^{\text {extr }}=a_{31} \cdot x_{1}+a_{32} \cdot x_{2}, \\
& \Delta g_{3}^{\min }(1,4,5,6)=6 \cdot 1-4 \cdot 4=-10
\end{aligned}
$$

$\Delta g_{3}^{\min }=-10, \quad \Delta g_{3}^{\min }=-10>-34$, inequality is not satisfied;

$$
\begin{gathered}
\Delta g_{3}^{\max }(3,1,5,6)=6 \cdot 3-4 \cdot 1=14, \\
\Delta g_{3}^{\max }(3,1,5,6)=6 \cdot 3-4 \cdot 1=14, \Delta g_{3}^{\max }=14, \text { the }
\end{gathered}
$$
inequality is not satisfied. Hence, on the subgraph (Fig. 3) there are no points of the set of partial permutations that would satisfy the constraint $g_{3}$.

It can be concluded that there are no points that would satisfy all the constraints.

All subgraphs of the set of partial permutations constructed according to Table 2 are checked in a similar way. Using the software that implements the solution algorithm, an optimal solution was obtained:

$$
F_{\text {max }}(1,5,3,4)=46,5 .
$$

It should be noted that when finding the optimal solution, 13 subgraphs out of 30 were considered, as well as 126 points out of a possible 360 , taking into account the verification of three constraints.

\section{Conclusion}

The article considers the problem of conditional optimization on a combinatorial set of partial permutations, presents an algorithm for its solution. Interpretation of the elements of the set of arrange-

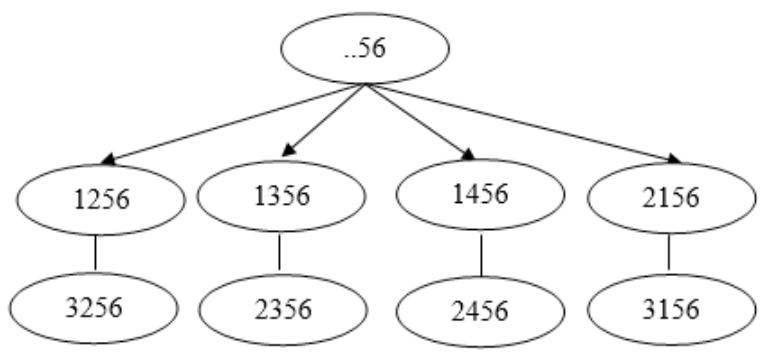

Fig. 3. Modified first subgraph of a set of partial permutations after constraints are met $g_{1}, g_{2}$

ments as points in Euclidean space allows one to obtain a linear form of the objective function. When considering additional constraints, the problem is to find the maximum of the linear objective function $F(x)$ on the combinatorial polytope $M_{n}^{k}(A)$ of allocations for which there is a graph $G(A)$.

The solution algorithm consists of four steps that allow you to build the edges and levels of the placement graph from the last elements of a point in the placement set. At each level, the fulfillment of the constraints is checked when finding the extrema of the increments of the constraints, without the need to calculate the entire constraint and consider all points of the set of partial permutations. If the extrema of the growth restrictions are not met, the algorithm allows cutting off a significant number of graph points, which is confirmed by the considered practical example. Of the possible 360 points of the set of partial permutations, when using the graph of the set of partial permutations, 126 points were considered, 13 subgraphs out of 30 , with three constraints in the problem. The example shows in detail all the steps of the solution algorithm for the first subgraph. Further research will focus on adapting the algorithm for other combinatorial sets using nonlinear objective functions.

\section{REFERENCES}

1. Sergienko I. V., Shilo V.P. Discrete Optimization Problems: Challenges, Analysis Techniques, and Solutions \{in Russian\}, Naukova Dumka, Kyiv (2003). 261 p.

2. Bernhard K., Jens V. Combinatorial Optimization, Theory and Algorithms. Springer-Verlag, Berlin, 2012. 627 p.

3. Colbourn C.J., Dinitz J.H. Handbook of Combinatorial Designs, Second Edition. CRC Press, 2010. 784 p.

4. Korte B., Vygen J. Combinatorial Optimization: theory and algorithms. Heidelberg; New York : Springer, 2018. 698 p.

5. Pardalos P.M., D-Z. Du, Graham R.L. Handbook of combinatorial optimization. New York : Springer, 2013. 3409 p. 
6. Papadimitriou C.H., Steiglitz K. Combinatorial optimization: algorithms and complexity. Mineola : Dover Publications, 2013. $528 \mathrm{p}$.

7. Hulianytskyi L. and Riasna I., "Formalization and classification of combinatorial optimization problems," Springer Optimization and its Applications, vol. 130, pp. 239-250, 2017.

8. Timofeeva N.K. Methods of Constructing Argument of Objective Function in Combinatorial Optimization Problems. Cybernetics and Systems Analysis. 2002. Vol. 38, N 6. P. 873-878.

9. Koliechkina L.N., Nahirna A.N. Solutions of the Combinatorial Problem with a Quadratic Fractional Objective Function on the Set of Permutations. Cybernetics and Systems Analysis. 2020. Vol. 56, N 3. P. 455-465.

10. Koliechkina L. N., Dvirna O. A., Nagornaya A. N. Modified Coordinate Method to Solve Multicriteria Optimization Problems on Combinatorial Configurations. Cybernetics and Systems Analysis. 2014. Vol. 59, N 4. P. 620-626.

11. Yakovlev S.V., Pichugina O. S. Properties of Combinatorial Optimization Problems Over Polyhedral-Spherical Sets. Cybernetics and Systems Analysis. 2018, Vol. 54, N 1. P. 99-109.

12. Yakovlev $S$. Convex extensions in combinatorial optimization and their applications. Springer Optimization Methods and Applications. 2017. Vol. 130. P. 567-584.

13. Koliechkina L. N., Dvirna O.A. Solving Extremum Problems with Linear Fractional Objective Functions on the Combinatorial Configuration of Permutations Under Multicriteriality. Cybernetics and Systems Analysis. 2017, Vol. 53, N 4. P. 590-599.

14. Donets G.P., Koliechkina L.N. Extremum Problems on Combinatorial Configurations [in Ukrainian], RVV, Poltava (2011). 309 p.

15. Stoyan, Y.G., Yakovlev, S.V., Pichugina, O.S. The Euclidean combinatorial configurations: a monograph. Constanta, Kharkiv. 2017., 268p.

16. Yakovlev, S.V. Formalization of spatial configuration optimization problems with a special function class. Cybernetics and Systems Analysis. 2019. Vol. 55, N 4. P. 512-523.

17. Semenova N.V., Kolechkina L.N. Vector Discrete Optimization Problems on Combinatorial Sets: Methods of Analysis and Solution [in Ukrainian], Naukova Dumka, Kyiv (2009). 266 p.

Received 24.11.2020

Л.М. Колєчкіна, доктор фізико-математичних наук, професор,

Лодзький університет,

вул. Банаха 22, Лодзь 90-238, Польща,

lkoliechkina@gmail.com

A.M. Нагірна, кандидат фізико-математичних наук, доцент,

Національний університет «Києво-Могилянська академія»,

04070, м. Київ, вул. Г. Сковороди, 2,

naghirnaalla@ukr.net

\section{ЗНАХОДЖЕННЯ ОПТИМАЛЬНОГО РОЗВ'ЯЗКУ} ЗАДАЧІ УМОВНОЇ ОПТИМІЗАЦІЇ НА ГРАФІ МНОЖИНИ РОЗМІЩЕНЬ

Вступ. Сформульовано оптимізаційну задачу на комбінаторній множині розміщень з додатковими обмеженнями. Розглянуто алгоритм розв'язання даного типу задач, який складається з чотирьох кроків. Алгоритм розв'язання полягає у побудові графу множини розміщень для знаходження оптимального розв'язку. Наведено приклад практичної реалізації представленого алгоритму.

Мета статті - представлення методу розв'язання задачі умовної оптимізації на графі множини розміщень i демонстрація практичного прикладу реалізації.

Методи. Метод розв'язання комбінаторної задачі з додатковими обмеженнями на графі.

Результати. Сформульовано модель задачі умовної оптимізації на множині розміщень. Одержано лінійну форму цільової функції шляхом інтерпретації елементів множини розміщень як точок евклідового простору. Розглянуто комбінаторний многогранник розміщень, для якого існує граф множини розміщень. Запропоновано алгоритм розв'язання даної задачі та продемонстровано його практичне застосування.

Висновки. Запропонований алгоритм розв'язання задачі умовної оптимізації передбачає представлення допустимої множини розміщень у вигляді графа, що дозволяє значно скоротити шлях пошуку оптимального розв'язку, про що свідчить розглянутий у статті практичний приклад.

Ключові слова: задача умовної оптимізації, оптимальний розв'язок, граф, підграф, множина розміщень, цільова функція, обмеження. 